\title{
Artificial Neural Network Model for Monitoring Oil Film Regime in Spur Gear Based on Acoustic Emission Data
}

\author{
Yasir Hassan Ali, Roslan Abd Rahman, and Raja Ishak Raja Hamzah \\ Department of Applied Mechanics and Design, Faculty of Mechanical Engineering, Universiti Teknologi Malaysia (UTM), \\ Johor Bahru, 81310 Johor, Malaysia
}

Correspondence should be addressed to Roslan Abd Rahman; roslan@fkm.utm.my

Received 28 December 2014; Accepted 2 March 2015

Academic Editor: Mickaël Lallart

Copyright (C) 2015 Yasir Hassan Ali et al. This is an open access article distributed under the Creative Commons Attribution License, which permits unrestricted use, distribution, and reproduction in any medium, provided the original work is properly cited.

The thickness of an oil film lubricant can contribute to less gear tooth wear and surface failure. The purpose of this research is to use artificial neural network (ANN) computational modelling to correlate spur gear data from acoustic emissions, lubricant temperature, and specific film thickness $(\lambda)$. The approach is using an algorithm to monitor the oil film thickness and to detect which lubrication regime the gearbox is running either hydrodynamic, elastohydrodynamic, or boundary. This monitoring can aid identification of fault development. Feed-forward and recurrent Elman neural network algorithms were used to develop ANN models, which are subjected to training, testing, and validation process. The Levenberg-Marquardt back-propagation algorithm was applied to reduce errors. Log-sigmoid and Purelin were identified as suitable transfer functions for hidden and output nodes. The methods used in this paper shows accurate predictions from ANN and the feed-forward network performance is superior to the Elman neural network.

\section{Introduction}

Predicting the performance of a gear system is a serious function, as it is a crucial component in machinery. Danger to human life and potentially large-scale economic consequences can result from failures that cannot be predicted. Periodic inspection is essential in gear teeth or bearings, so that crack propagation or the other damage can be identified beforehand. Typical failures in gears are generally associated to bending, fatigue, contact fatigue, wear, and scuffing, all of which can be monitored by testing vibration and acoustic signals, temperature, torque, and lubrication film thickness. This can be carried out through continuous or online monitoring. Damage to gear teeth alters the parameters originating in the gear shaft. Damage also affects the oil film thickness and the type of wear that occurs [1].

The consequences of lost production and decreased reliability due to unplanned shutdown have a serious impact; thus machine performance monitoring is increasingly important in industry. The first step to monitor any deterioration is to establish a monitoring programme which can guide maintenance decisions. A number of monitoring methods for machinery with rotating components are available, including monitoring the lubrication, vibration, and acoustic emissions $[2,3]$.

Emerging technologies, such as artificial intelligence (AI) techniques and complex computational analysis, have led to the advancement in machine condition monitoring. Artificial intelligence has several advantages as compared to the traditional mathematical modelling and statistical analysis. This includes dispensing of the necessity for detailed system behavior knowledge which can be replaced by relatively simple computational methods [4].

The prediction for the condition of moving components in machines can be assessed by measuring the lubricating oil film thickness. This has been a typical approach applied by numerous researchers in the past. An adequate lubrication regime is essential to prevent or reduce surface wear on gear teeth. The ability to predict and rectify wear-related damage will improve the performance of gear transmission systems. 
The established methods have to include monitoring the performance that can detect changes in vibration, sound, wear, and lubricant behavior $[5,6]$.

In the past, research has been carried out to correlate acoustic emission with specific lubricant film thickness in spur gears. The method used to establish the relationship involved spraying liquid nitrogen onto a rotating gear wheel. This lowered its operating temperature and changed the response of the lubricant under a range of load and speed conditions [7]. Höhn and Michaelis have discussed the effect on gear failure due to rise in temperature [8]. Nondestructive acoustic emission (AE) testing showed a direct correlation between the root mean square (RMS) value of the signals and the specific film thickness $(\lambda)$. The AE RMS measures were particularly sensitive to detect specific film thickness changes [9-11].

The decision to apply ANN modelling in this research was based on its suitability and potential existence in wide range of applications to recognize specific patterns that can lead to the detection, classification, and diagnosis of changes in performance [12-19]. The particular application used is to identify and characterize the gear failure $[1,3]$. In order to identify the regime and estimate the performance of the oil film thickness, feed-forward and Elman neural networks are suitable to monitor gear operations and potentially can accurately diagnose faults. These methods analyze the RMS and temperature as an input and the oil film thickness as the predicted output. By adopting an ANN-based system, the analysis is efficient and the incidence of error is low. Figure 1 shows the flowchart indicating the process of applying ANN to monitor the condition of gear. This work represents the first attempt to apply ANN in monitoring oil film thickness in spur gear depending on the temperature and acoustic emission signal only to assess the oil film thickness condition of the gear. The designed ANN shall facilitate the identification of oil film regime and the gear tooth wear and surface failure can be controlled before fault development. It is anticipated that this area of research can potentially result in a wide range of applications in preventing fatal breakdown in the rotating machinery.

\section{Methodology}

2.1. Acoustic Emission Signals. Acoustic emission signals are outside human hearing and occur on the surface or from within materials when elastic waves at $20 \mathrm{kHz}-1 \mathrm{MHz}$ are released [20]. The waves are sent from an emission source and transferred to the surface by the transmission medium. The low displacement or high frequency mechanical waves can be picked up as electronic signals. The signal strength can be increased by using a preamplifier before the data are interpreted by the AE equipment $[21,22]$. The data used in this research were taken from earlier research $[7,9,10]$. The three main factors affecting the AE signal in these experiments are speed of rotation, applied torque (load), and the oil temperature. The most significant factor is the changes in the temperature of the lubricant. The data arising from the torque (applied load) and speed are of lesser importance [23].

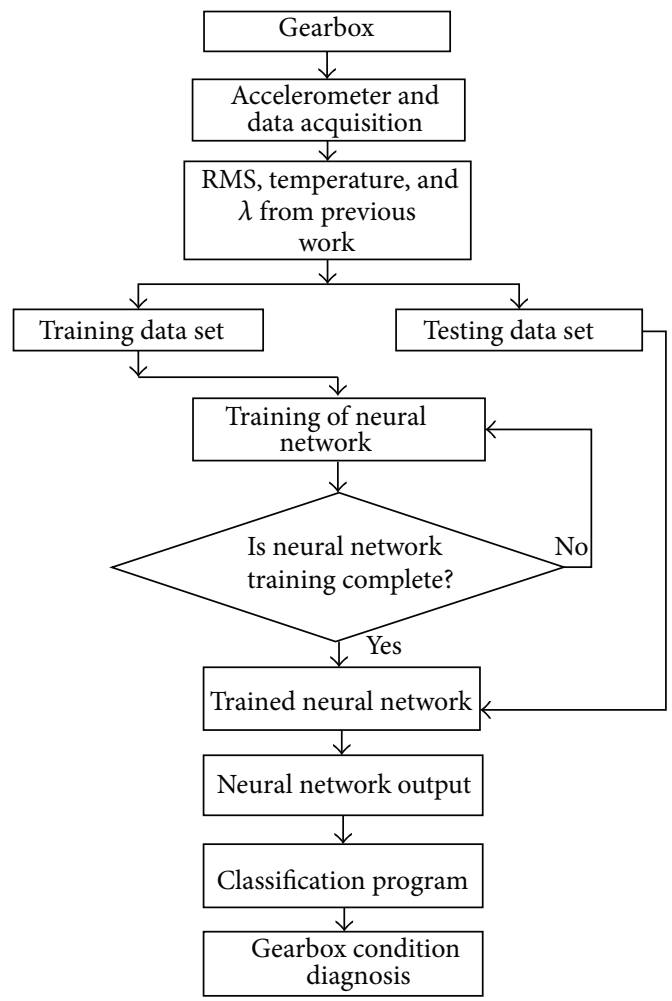

FIGURE 1: ANN training and testing of condition monitoring system.

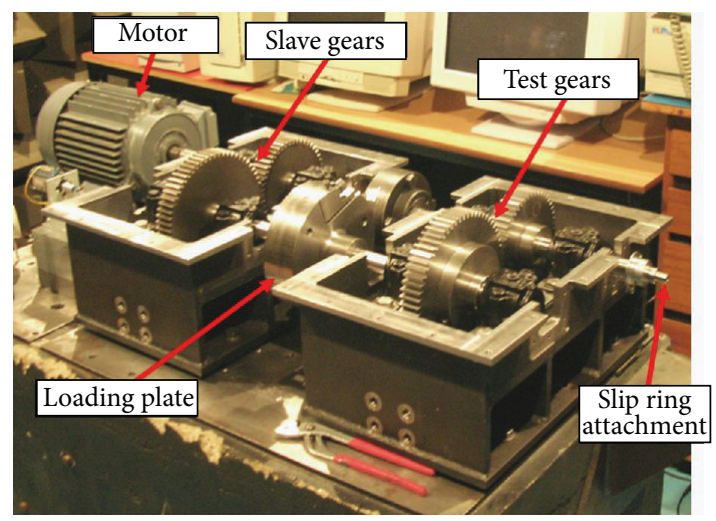

FIGURE 2: Back-to-back test gearbox arrangement [9].

2.2. Experimental Setup and Data Acquisition System. The test rig used in these experiments was a standard backto-back gearbox with oil bath lubrication as illustrated in Figure 2. A summary of the test gear specifications is listed in Table 1. The tests were carried out under extreme pressure using Mobil MOBILGEAR 636 as the lubricant. The selection of the lubricant was made to reduce the incidence of natural pitting and wear, and the lubricant properties are summarized in Table 2.

The setup includes a model WD wideband AE sensor capable of picking up relatively flat responses in the range $100 \mathrm{kHz}-1 \mathrm{MHz}$ with the operating temperature range of -65 to $177^{\circ} \mathrm{C}$ (Physical Acoustic Corp.). The AE signals from the rotating test pinion were transmitted to a commercial data 
TABLE 1: Test gears specifications.

\begin{tabular}{lc}
\hline Number of teeth, pinion : gear & $49: 65$ \\
Base diameter, pinion : gear $(\mathrm{mm})$ & $138.13: 183.24$ \\
Pitch diameter, pinion : gear $(\mathrm{mm})$ & $147.00: 195.00$ \\
Tip diameter, pinion : gear $(\mathrm{mm})$ & $153.00: 201.00$ \\
Contact ratio & 1.33 \\
Module $(\mathrm{mm})$ & 3.00 \\
Addendum modification coefficient & 0 \\
Surface roughness, Ra $(\mathrm{mm})$ & 2.00 \\
Face width $(\mathrm{mm})$ & 30.00 \\
Pressure angle $\left(^{\circ}\right)$ & 2.00 \\
Modulus of elasticity $(\mathrm{GPa})$ & 228.00 \\
\hline
\end{tabular}

TABLE 2: Lubricant properties.

\begin{tabular}{lc}
\hline Viscosity & \\
$40^{\circ} \mathrm{C}(\mathrm{cSt})$ & 680.0 \\
$100^{\circ} \mathrm{C}(\mathrm{cSt})$ & 39.2 \\
Density at $15.6^{\circ} \mathrm{C}(\mathrm{kg} / \mathrm{L})$ & 0.91 \\
Viscosity index & 90.0 \\
Pour point $\left({ }^{\circ} \mathrm{C}\right)$ & -9.0 \\
Flash point $\left({ }^{\circ} \mathrm{C}\right)$ & 285.0 \\
Pressure viscosity coefficient, $\alpha\left(\mathrm{mm}^{2} / \mathrm{N}\right)$ & $2.2 \times 10^{-8}$ \\
\hline
\end{tabular}

acquisition system by silver contact slip rings (Figure 2). During testing, the signals from the sensor were preamplified at 20 and $40 \mathrm{~dB}$. Figure 3 shows the fixing of a sensor to the gear pinion with strong adhesive. Two iron-constantan thermocouples (type J) capable of measuring gear metal temperatures in the range $0-200^{\circ} \mathrm{C}$ were mounted on the test pinion and third one was located inside the oil bath to measure the lubricant temperature. Mass of the thermocouple and the $\mathrm{AE}$ sensor are considered to be small; therefore unbalance is considered to be negligible.

The gearbox test rig was set to continuously record $\mathrm{AE}$ RMS signals which were captured by software interfaced with an analogue-to-digital converter (ADC). The torque loading parameters were 60,120 , and $250 \mathrm{Nm}$ and the gearbox was run at 700 and $1450 \mathrm{rpm}$. The selected speed represented approximately one complete revolution of the pinion at $700 \mathrm{rpm}$. Using the accumulated squared ADC values, the RMS could then be calculated. An antialiasing filter was used before signal sampling at the ADC. The AE waveform sampling rate was $10 \mathrm{MHz}$ and the digital filtering range was 100 $1200 \mathrm{kHz}$. The temperature sampling rate was set at $1 \mathrm{~Hz}$ and the accuracy was $70.1 \%$ on a $1^{\circ} \mathrm{C}$ resolution $[7,9]$.

The selection of lubrication system for the test rig was based on gear tangential speed. Methods of lubrication that are generally used in gears are three primary methods.

They are grease lubrication ( 0 to $6 \mathrm{~m} / \mathrm{s}$ tangential gear speed), splash lubrication (4 to $15 \mathrm{~m} / \mathrm{s}$ tangential gear speed), and forced oil circulation lubrication (above $12 \mathrm{~m} / \mathrm{s}$ tangential gear speed). The splash or oil bath lubrication system was selected for the purpose of this research programmer since

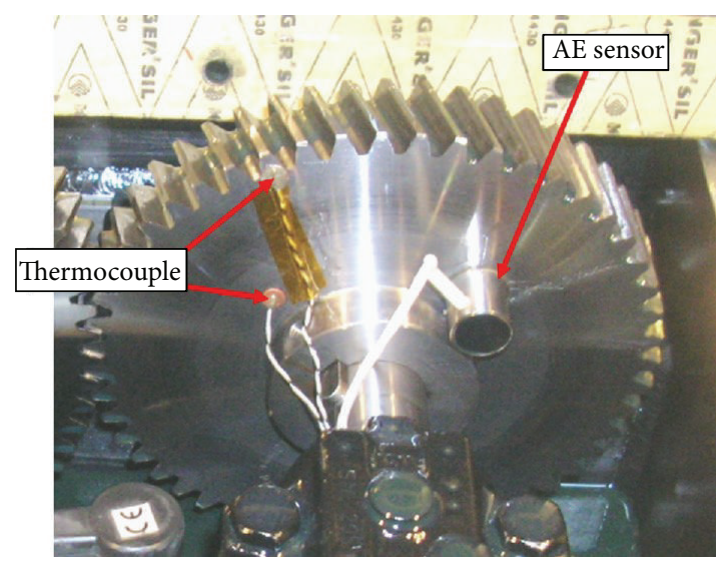

FIGURE 3: AE sensor and thermocouple location on test pinion gear [9].

the tangential speed during the test mostly ranges from $5.39 \mathrm{~m} / \mathrm{s}$ to $12.20 \mathrm{~m} / \mathrm{s}$.

2.3. Mathematical Principles. Oil lubrication prevents the gear teeth from coming into direct contact and reduces friction, vibration, heat buildup, and corrosion. The predicted fatigue life of the gears can be understood by the lambda $(\lambda)$ ratio. The operating determinants affecting the $\lambda$ ratio calculations are temperature, load, surface roughness, and gear speed [11]. The $\lambda$ ratio is defined as the oil film thickness $(h)$ divided by the composite surface roughness $\left(\sigma_{\text {rms }}\right)$ as derived in

$$
\lambda=\frac{h}{\sigma_{\text {rms }}},
$$

where

$$
h=\frac{k\left(\eta_{o} u\right)^{0.7} R^{0.43}}{w^{0.13}} \mu \mathrm{m} .
$$

And $k=1.6 \alpha^{0.6} E^{0.03}, \eta_{o}$ is dynamic viscosity in Pa.s, $\mu$ is entraining velocity in $\mathrm{m} / \mathrm{s}, R$ is equivalent radius in $\mathrm{m}, w$ is load applied along the line of contact in $\mathrm{N} / \mathrm{m}, \alpha$ is pressure viscosity coefficient in $\mathrm{mm}^{2} / \mathrm{N}$, and $E$ is modulus of elasticity of the gear in $\mathrm{Pa}$.

The film thickness is indicative of the lubrication regime between two rough surfaces. The film is affected by high pressure contact and sliding, which causes heat generation and changes in physical properties. Typical operating conditions cause the lubricant to become thin, reducing protection against rubbing at the surfaces and resulting in lubricant failure. The characteristics of the lubricant are therefore crucial to maintain the minimum film thickness under specific operating conditions and this would require a sufficiently large $\lambda$ ratio [1].

Three different lubrication regimes can be distinguished depending on the lubricant film thickness which are hydrodynamic lubrication (HL), elastohydrodynamic lubrication (EHL), and boundary lubrication (BL). Mixed lubrication is an intermediate regime between elastohydrodynamic and 
boundary lubrication. Full hydrodynamic lubrication would normally occur at $\lambda>10$. This condition would produce minimal friction and wear with no direct surface interaction. Pressure transmitted through the lubricant would represent the only likely fatigue mechanism. Gears generally operate in the elastohydrodynamic regime $(2<\lambda<10)$ and at a lower film thickness ratio there is likely to be contact on the moving surfaces from asperities in the lubricant producing wear. The effect of thermal and pressure conditions at the surfaces can result in larger asperities in the lubricant and lead to film breakdown which causes severe wear, such as scuffing. Boundary and dry lubrication would typically occur at $\lambda<2$. Figure 4 shows the "Stribeck curve" illustrating the $\lambda$ values in the various lubrication regimes [20].

2.4. Artificial Neural Networks. Modelled on thinking mechanisms that have been mapped in the human brain, an ANN architecture consists of input and output layers, several neuron layers, and one or more hidden layers. Information flows through different layers from the input to the output and each layer is connected by neurons to adjacent layers. The layered network matrix connections will assign numerical values based on the connective arcs and the weight they are given, which can be adjusted during the training phase.

In this study, oil temperature and acoustic emission signals are the inputs and the specific film thickness $(\lambda)$ is the output used to build the exploratory artificial neural network. The function of an ANN is to describe a system which cannot be readily interpreted by other analytical methods. It is a particularly efficient way to classify large amounts of input and output data which do not have an obvious linear relationship. Nonlinear relationships can be developed in an ANN where system information is absent, which is the advantage of neural networks.

When designing a neural network there are a number of different parameters that must be decided. Some of these parameters are the number of training iterations, the number of layers, the learning rate, the number of neurons per layer, and the transfer functions, and so forth.

The ANN parameter is generally performed by a developer through a trial-and-error procedure [24]. Number of training iterations used her is 1000 epochs; the goal of training is zero error. The used parameter in building ANN and why this parameter is selected in this work are explained below.

\subsubsection{Feed-Forward Back-Propagation Neural Networks} (FFBP). Multilayer FFNN modelling can be used in fault detection and diagnosis in rotating machinery. The neural networks are trained using a back-propagation algorithm to estimate lubrication film thickness $[1,25]$. The term feedforward relates to the way in which patterns are processed and recalled where the neurons are only connected forward. Each network layer is linked to the next, for example, from the input to the hidden layer. Back-propagation is a form of supervised training in which the network receives input samples which are associated to the predicted output. A comparison is made between predicted and actual outputs associated with a given input. Using the predicted outputs,

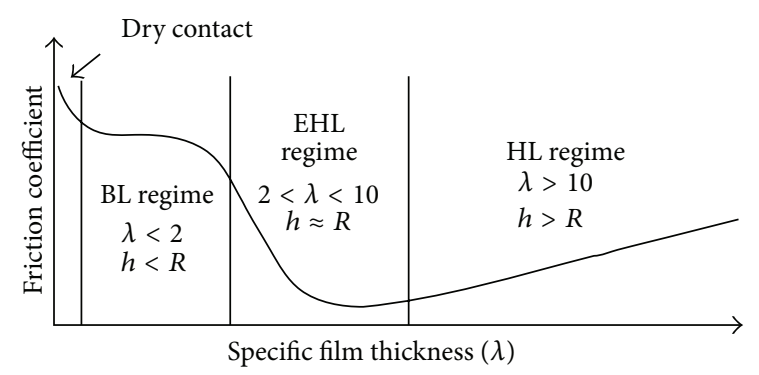

Figure 4: The Stribeck curve and specific film thickness $(\lambda)$.

the back-propagation training algorithm calculates an error related to the actual output. This adjusts the weighting of the layers backwards from the output layer to the input layer. The feed-forward back-propagation neural network modelled the film thickness. The computational modelling software functions were supported by the MATLAB ANN toolbox. The toolbox functions include identifying the training algorithm, training and transfer functions, the types of input and hidden layers, the initial weights and bias values, and the other mathematical analysis that results in accurate prediction by an ANN structure.

Tan-sigmoid (nonlinear outputs between -1 and +1 ), Logsigmoid (nonlinear outputs between 0 and +1 ), and transfer function linear outputs (between -1 and +1 ) can be used in hidden and output layers. Different transfer functions are explained in Figure 5, together with the structure of feedforward back-propagation. The quality of results is dependent on the selection of a suitable transfer function in the hidden and output layers. In this study the Log-sigmoid transfer function was used by the network in the hidden layer and the Purelin linear transfer function was used in the output layer.

One of the earliest training algorithms was developed by Levenberg and Marquardt (LM). It is commonly used in conjunction with feed-forward neural networks. It can resolve a number of problems in nonlinear multilayered networks [26].

2.4.2. Elman Network (EN). This is a semirecursive neural network which identifies patterns from a sequence of values by the back-propagation through time learning algorithm. First proposed by Jeffrey Elman in 1990, it is a recurrent neural network that enables sequential learning and recognition of patterns in series of values or events which unfolded over time and can be predicted. In Figure 6, an Elman network is shown in which there is a recurrent first layer, as opposed to a conventional, two-layer network. Values from a previous time step can be stored and used in the current time step. The stored information can be used in the future and this enables temporal and spatial pattern learning. Recognition and generation of both types of patterns are possible in Elman networks.

The Elman ANN uses the Log-sigmoid and Purelin transfer functions in its hidden layer and output layers, respectively, providing approximation to any function. The Levenberg-Marquardt (LM) training algorithm also 

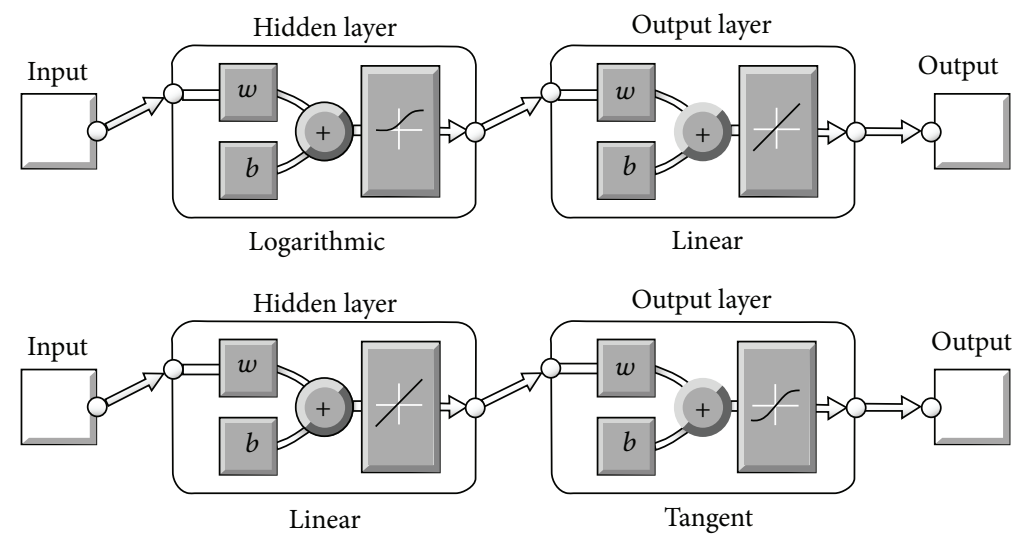

FIGURE 5: ANN structure and transfer function types of feed-forward back-propagation.

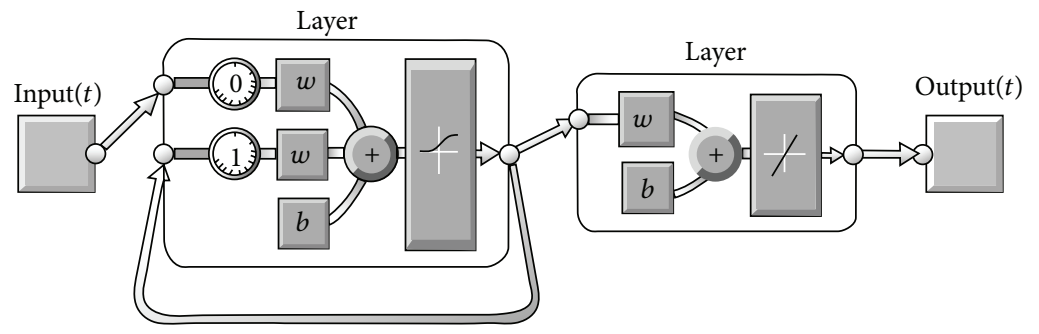

FIgURE 6: ANN structure and transfer function types of Elman network.

improves performance compared to other network training methods.

2.4.3. Training and Testing Strategies. Training ( $\mathrm{Tr}$ ) in a neural network is the most intense and important computation that takes place. When the training is complete, rapid identification of any unknown input samples in the network is possible. A relationship between input data can be established, even if arising from spurious signals.

During training, the node weighting is continually adjusted to get as close to the real value associated with all available inputs. This involves extensive amounts of information and is a very important process to improve the functionality of the network. However, once an overfitting is identified the analytical processing is halted.

Overfitting takes place when the model is performing well during training; then it starts to decline when tested with unseen data. Cross-validation which estimates the performance of a predictive model can overcome overfitting. Training and validation require two distinct data sets. The mean squared error (MSE) of the validation data first decreases when overfitting takes place, reaches a minimum, and then increases. However, the training data MSE continues to decrease. It is assumed that when the validation data set MSE increases, the regression algorithm is overfitting the training data and training is stopped [26].

The supervised training method was used in this study. The network has an input layer ( 2 neurons), a hidden layer (5 neurons), and an output layer (1 neuron). The number of neurons in the hidden layer is assumed to be the number of inputs multiplied by two, plus one (number of inputs $\times 2+1$ ) [27]. During testing (Ts), the real output is compared to the network output. At this stage the weightings are not adjusted and the data are collected, converted, and a comparison is made. Each category of data displayed on a network consists of a set of inputs and outputs. Two different sets of data are also used for training and testing. The network is suitable for use when testing shows it is able to process correct answers.

2.5. Statistical Error Analysis. In this research, performance of a network is evaluated by statistical error analyses which identify the most suitable model. Three types of error analysis were used to evaluate and compare the models.

2.5.1. Mean Squared Error (MSE). An error is the difference between the predicted and actual value. The MSE finds the average of the squares of the predicted errors, which corresponds to the risk factor the network represented, because of quadratic or square error loss. The cause of the difference is due to either the random approach or the fact that certain information has not been processed during the prediction, which would have produced a more accurate estimate. If $Y_{i}$ is a vector of $\mathrm{n}$ predictions and $Y_{i}$ is the vector of the actual values, then the (estimated) MSE of the predictor is

$$
\mathrm{MSE}=\frac{1}{n} \sum_{i=1}^{n}\left(\dot{Y}_{i}-Y_{i}\right)^{2} .
$$


TABLE 3: Statistical error value in training and testing.

\begin{tabular}{lcccccc}
\hline \multirow{2}{*}{ Network } & \multicolumn{2}{c}{ MSE } & \multicolumn{2}{c}{ MAE } & \multicolumn{2}{c}{ MAPE } \\
& Training & Testing & Training & Testing & Training & Testing \\
\hline Elman & $3.4684 \times 10^{-4}$ & $6.5959 \times 10^{-4}$ & $7.2 \times 10^{-3}$ & $2.31 \times 10^{-2}$ & $2.388 \times 10^{-1}$ & $4.58 \times 10^{-1}$ \\
FFBP & $1.3524 \times 10^{-5}$ & $5.848 \times 10^{-4}$ & $2.6 \times 10^{-3}$ & $2.18 \times 10^{-2}$ & $1.617 \times 10^{-1}$ & $4.548 \times 10^{-1}$ \\
\hline
\end{tabular}

2.5.2. Mean Absolute Percentage Error (MAPE). The MAPE is a method which can measure the accuracy of constructing fitted time series values and estimating the trend. Accuracy is measured in percentage error using the following equation:

$$
\text { MAPE }=\frac{1}{n} \sum_{i=1}^{n}\left|\frac{Y_{i}-\dot{Y}_{i}}{Y_{i}}\right|,
$$

where $Y_{i}$ is the actual value and $Y_{i}$ is the predicted value.

The absolute value is summed for each fitted or predicted point in time, divided by the number of fitted points $(n)$ and multiplied by 100 .

2.5.3. Mean Absolute Error (MAE). The MAE is a quantity comparing the closeness of predicted and actual values given by the following equation:

$$
\operatorname{MAE}=\frac{1}{n} \sum_{i=1}^{n}\left|\dot{Y}_{i}-Y_{i}\right| .
$$

It is commonly used to predict error when analyzing time series.

2.6. Data Preparation and Simulation. In this study, the data was taken from previous research to investigate and understand the influence of specific film thickness $(\lambda)$ on the generation of AE activity during spur gear mesh under various operating conditions $[7,9,10]$. The gearbox was run at three different torque loading conditions which are $60 \mathrm{Nm}$ (L1), $120 \mathrm{Nm}$ (L2), and $250 \mathrm{Nm}$ (L3). The two speeds used were $700 \mathrm{rpm}$ (S1) and $1450 \mathrm{rpm}$ (S2).

In this study of the lubrication regimes, the data was divided into 6 categories; each category represents one load and speed condition. The first load and speed condition is (S1L1), with the speed at $700 \mathrm{rpm}$ (S1) and torque loading conditions $60 \mathrm{Nm}$ (L1). The data for temperature, acoustic emission, and specific film thickness comprise 1000 sets each and the same for (S1L2), (S1L3), (S2L1), 18 (S2L2), and (S2L3). This study has a total of 6 load and speed conditions for 2 speed and 3 torque loading conditions.

The simulation of the network was done using SIMULINK of MATLAB and then tested by the test data set. The data set is comprised of $20 \%$ for each input and output, variables for tow speed and three load conditions $(2 \times$ 3 ). Classification program was designed and used to classify the prediction output to hydrodynamic lubrication (HL), elastohydrodynamic lubrication (EHL), and boundary lubrication (BL) based on the specific film thickness magnitude.

The input data for ANN are temperature and RMS of the acoustic emission signal. The output data is the specific
TABLE 4: FFBP performance.

\begin{tabular}{lccc}
\hline FFBP network & MSE & MAE & MAPE \\
\hline S1L1 & $2.6965 \times 10^{-4}$ & $1.3 \times 10^{-3}$ & $3.127 \times 10^{-2}$ \\
S1L2 & $1.0253 \times 10^{-4}$ & $7.05 \times 10^{-3}$ & $1.784 \times 10^{-1}$ \\
S1L3 & $1.3524 \times 10^{-5}$ & $2.6 \times 10^{-3}$ & $1.617 \times 10^{-1}$ \\
S2L1 & $9.4002 \times 10^{-5}$ & $6.6 \times 10^{-3}$ & $2.359 \times 10^{-1}$ \\
S2L2 & $7.1003 \times 10^{-4}$ & $1.01 \times 10^{-2}$ & $8.836 \times 10^{-1}$ \\
S2L3 & $1.1 \times 10^{-3}$ & $1.5 \times 10^{-2}$ & $9.447 \times 10^{-1}$ \\
\hline
\end{tabular}

film thickness. This data was divided into two sets which are training and testing. From all the data $80 \%$ was used for training and $20 \%$ for testing.

\section{Results and Discussion}

Neural network toolboxes in MATLAB use many types of training algorithms and training functions. Feed-forward back-propagation networks with the Levenberg-Marquardt training algorithm and Elman back-propagation with the Levenberg-Marquardt training algorithm were used in this study to improve oil film regime predicting accuracy. The number of neurons was determined to be (number of inputs $x$ $2+1$ ) neurons [27].

Since the study included two speeds and three load conditions, by using two networks (12 load and speed conditions), a lot of information from each condition was obtained. For that reason, only the best and the poorest performances from the six conditions in each network are discussed.

Table 3 shows the value of the three statistical errors which have been done in training and testing performance for both networks. These three statistical errors have been used to assess the performance of the networks. The result indicates that the performance of networks in training is better than in testing for both Elman and FFBP, whereas the value of the errors measurement in training is less than in testing. (Note that the difference in error between the networks is much larger during training as compared to testing.)

3.1. FFBP Result. The advantage of FFNN is that it is easy to construct. During the development of FFNN, after all the parameters (such as input layer, hidden layer, and output layer) are confirmed, the weights and biases of the network are saved as one model.

Table 4 shows the performance of the FFBP network for the six load and speed conditions. The FFBP network represents very good results for the third load and speed conditions (S1L3) where the MSE, MAE, and MAPE values are very small compared to the other conditions. At the same 


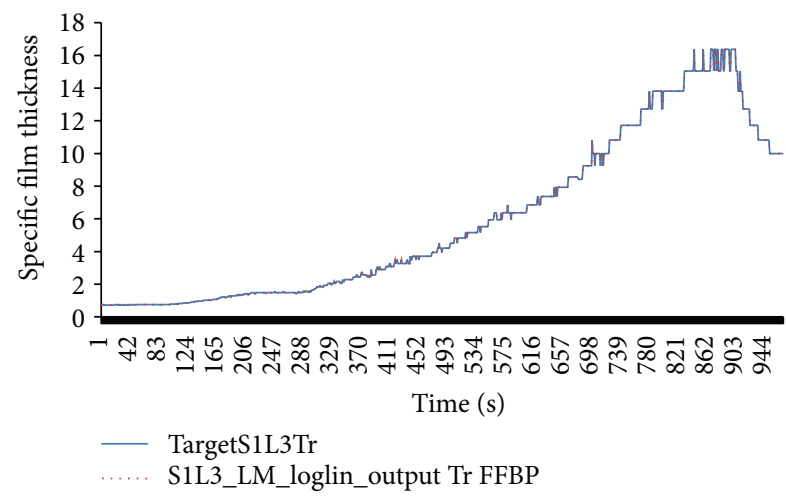

FIGURE 7: FFBP network training output and the target.

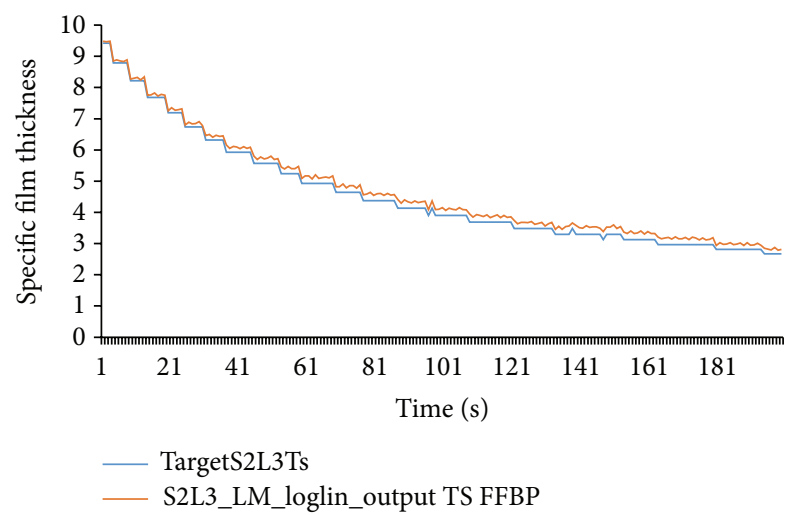

FIGURE 8: FFBP network testing output and the target.

time, the value of the statistical errors measurement for load and speed conditions (S2L3) is higher than the other conditions because the performance of the network for (S2L3) is less than the others.

Figure 7 illustrates the target for (S1L3) and the FFBP network training output for this condition. The FFBP provided an excellent prediction, where the prediction and the target were almost the same as MSE equal to $1.3524 \times 10^{-5}$.

On the other hand, the network delivered for (S2L3) was not fully satisfactory with the MSE equal to $6.1 \times 10^{-3}$, which was made clear when testing this network with unseen data. As shown in Figure 8, there are some differences between the predicted and the actual outputs.

The MSE error is plotted against a number of epochs of training for S1L3 and S2L3. Figure 9 shows that the best validation performance is $1.5007 \times 10^{-5}$ for S1L3 and $4.5334 \times 10^{-3}$ for S2L3. As seen in the two figures, after 1,000 iterations for S1L3 and 369 iterations for S2L3, the error comes down and flattens out revealing no more significant change in error with a further increase in the number of epochs. There are also less testing and validation errors, as seen from close proximity of the curves.

The FFBPP network is trained and regression performed on its targets and outputs. Regression testing can be used for testing the correctness of a module and for tracking the quality of its output. Figure 10 displays the regression test

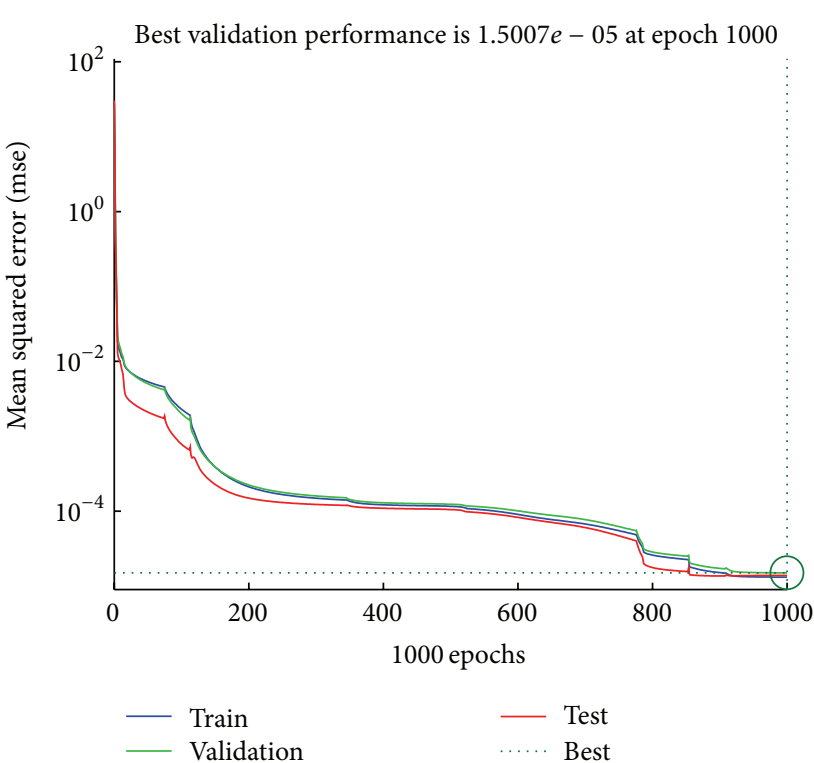

(a)

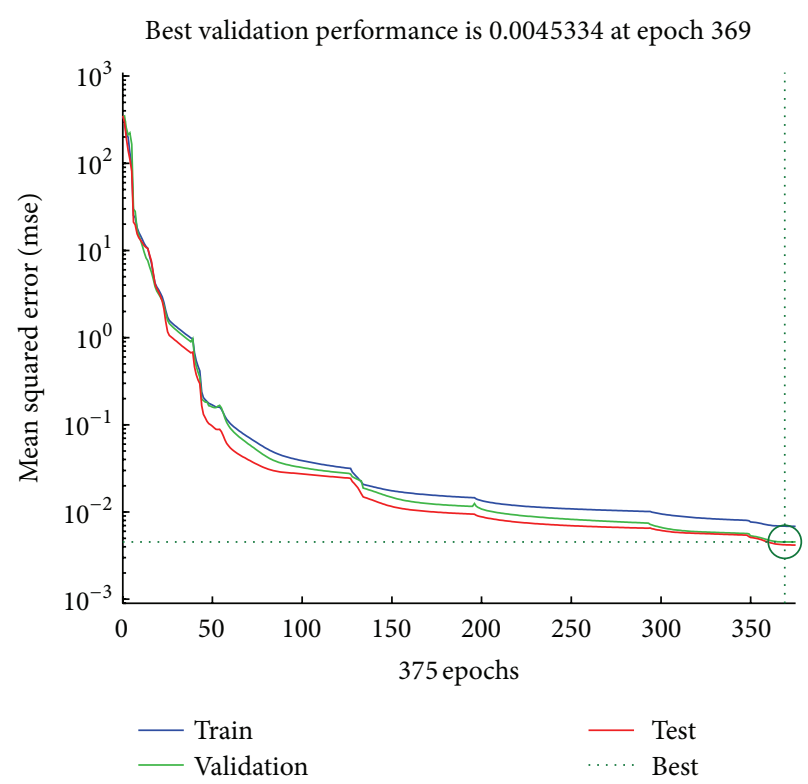

(b)

FIGURE 9: Validation performance for FFBP network: (a) S1L3 and (b) S2L3.

between the network output and the target for training, validation, and testing for (S1L3) for this load and speed conditions. The training, validation, and testing indicate a very good fit where the simple liner correlation $R=0.99999$. This value indicates that the network output is consistent with the target.

3.2. Elman Result. The EN was selected in this paper for a modelling process because of its ability to learn temporal patterns and store information for future reference.

The Elman network for load and speed conditions (S1L1) gave a great performance, as can be seen from Table 5 

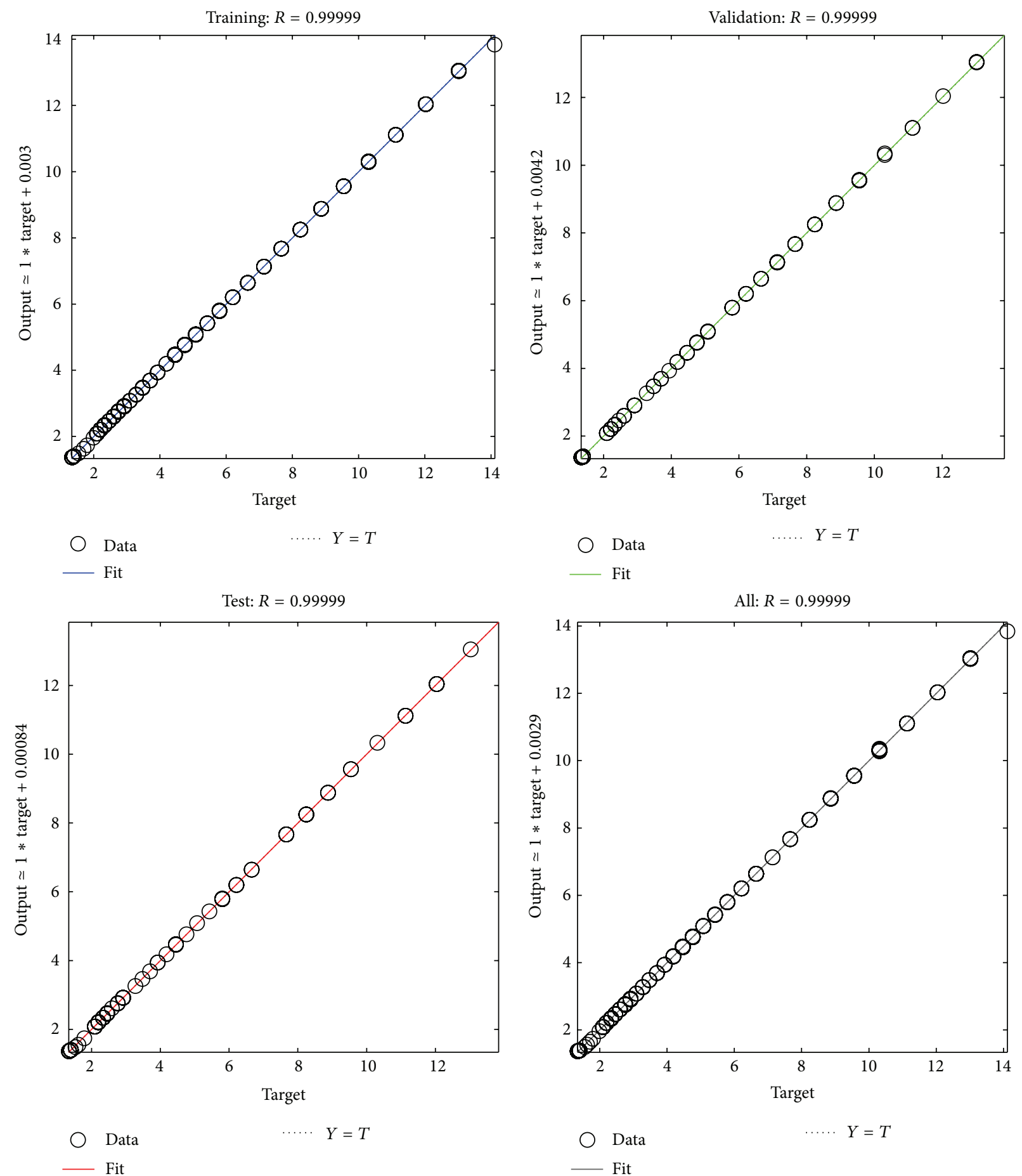

FIGURE 10: Feed-forward network regression performed on its targets and outputs. 
TABLE 5: Elman network performance.

\begin{tabular}{lccc}
\hline Elman network & MSE & MAE & MAPE \\
\hline S1L1 & $9.7594 \times 10^{-4}$ & $1.5 \times 10^{-3}$ & $3.47 \times 10^{-2}$ \\
S1L2 & $3.4684 \times 10^{-4}$ & $7.2 \times 10^{-3}$ & $2.388 \times 10^{-1}$ \\
S1L3 & $2.1 \times 10^{-3}$ & $2.73 \times 10^{-2}$ & 1.0187 \\
S2L1 & $1.16 \times 10^{-2}$ & $6.78 \times 10^{-2}$ & 2.012 \\
S2L2 & $3.5 \times 10^{-3}$ & $1.08 \times 10^{-2}$ & $4.599 \times 10^{-1}$ \\
S2L3 & $2.1 \times 10^{-3}$ & $1.91 \times 10^{-2}$ & 3.5312 \\
\hline
\end{tabular}

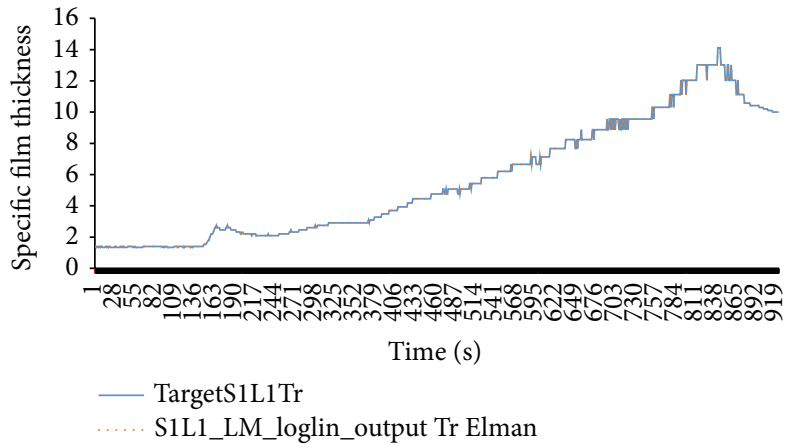

FIGURE 11: Elman network training output and the target.

where it gave the smallest value for the three-statistical errors measurement compared to the other 5 load and speed conditions. Also, the network provided the exact prediction for (S1L1). This is obvious from Figure 11, where the network output matches the target and there is no difference between them.

Meanwhile, the network performance provided a less accurate prediction for S2L1, since the value of the error measurement is higher than the other load and speed conditions (as shown in Table 5). Also, when testing the network there were some differences between the network output and the target. This is clear from the comparison between actual output and the prediction as displayed in Figure 12.

Figure 13 displays the validation performance for EN, where the error comes down and the best validation performance is $6.413 \times 10^{-5}$ for S1L1 after 459 iterations and $8.9168 \times$ $10^{-3}$ for S2L1 after 208 iterations.

The result above indicates that the networks performed very well during training and validation processes for load and speed conditions (S1L1) and less for the other load and speed conditions, especially for (S2L1).

3.3. Comparison between FFBP and Elman Networks. This work is important in confirming the optimal network that can be used for predicting the oil film thickness. For that purpose, a comparison between FFBP and Elman networks is done in order to select the most suitable network for the modelling process. The network which produces the lowest validation error during training is selected as the optimum network.

Table 6 shows the best validation performance for FFBP and Elman networks during training. The observation from this table is that FFBP gave a lower validation error for all load and speed conditions.

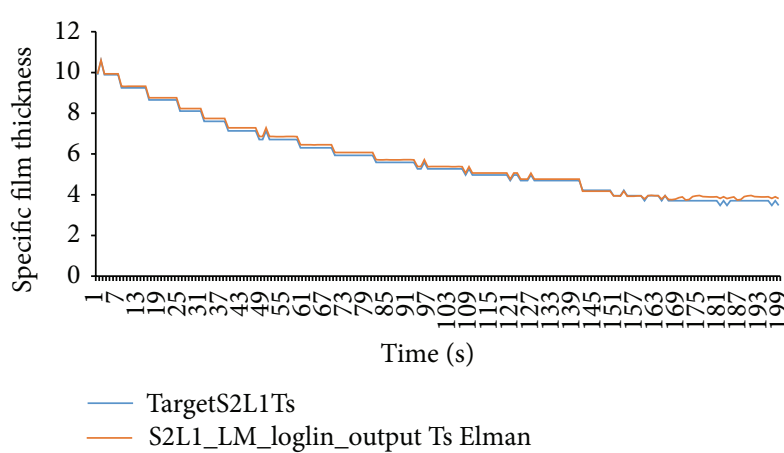

FIGURE 12: Elman network testing output and the target.

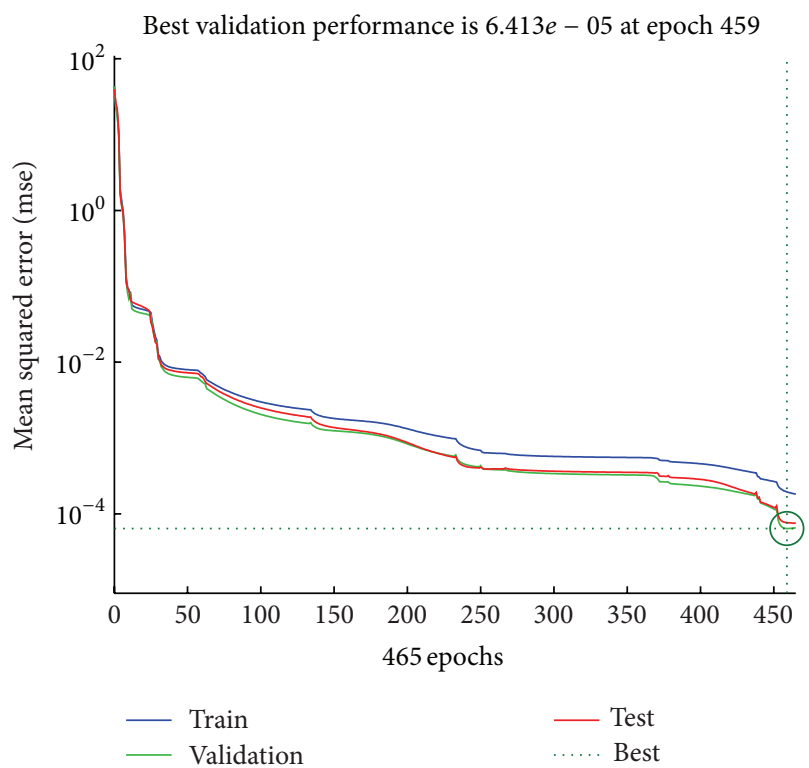

(a)

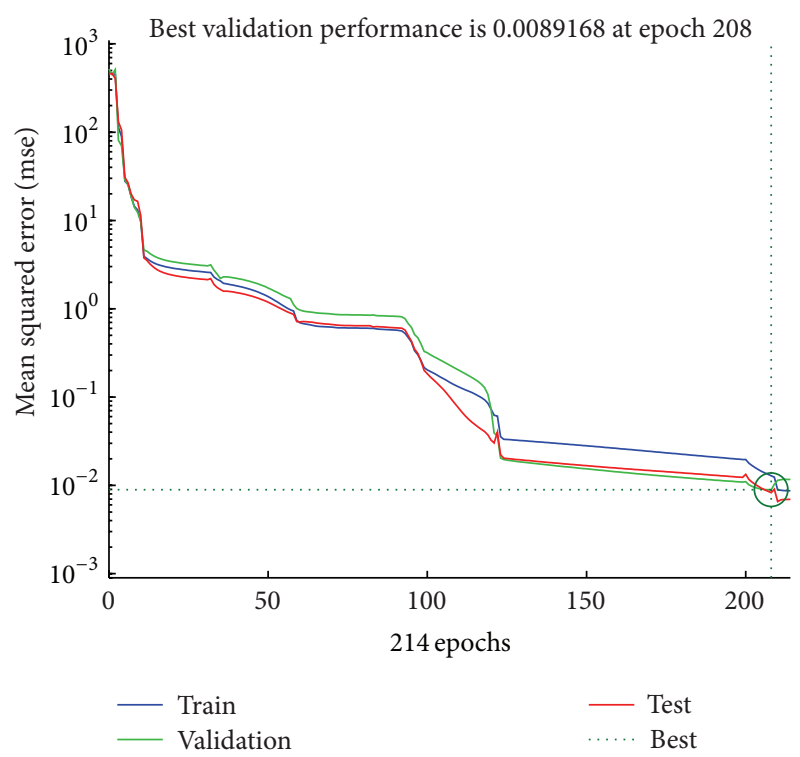

(b)

FIGURE 13: Validation performance for Elman network: (a) S1L1 and (b) S2L1. 
TABLE 6: Best validation performance for FFBP and Elman networks during training.

\begin{tabular}{lcccc}
\hline \multirow{2}{*}{ Load and speed condition } & \multicolumn{2}{c}{ FFBP network } & \multicolumn{2}{c}{ Elman network } \\
& Best validation & Iteration number & Best validation & Iteration number \\
\hline S1L1 & $6.2725 \times 10^{-5}$ & 247 & $6.4130 \times 10^{-5}$ & 459 \\
S1L2 & $1.9810 \times 10^{-5}$ & 993 & $6.9132 \times 10^{-5}$ & 351 \\
S1L3 & $1.5007 \times 10^{-5}$ & 1000 & $2.5177 \times 10^{-3}$ & 420 \\
S2L1 & $8.6352 \times 10^{-5}$ & 1000 & $8.9168 \times 10^{-3}$ & 208 \\
S2L2 & $4.6211 \times 10^{-4}$ & 131 & $2.6495 \times 10^{-3}$ & 883 \\
S2L3 & $4.5334 \times 10^{-3}$ & 369 & $5.1342 \times 10^{-3}$ & 438 \\
\hline
\end{tabular}

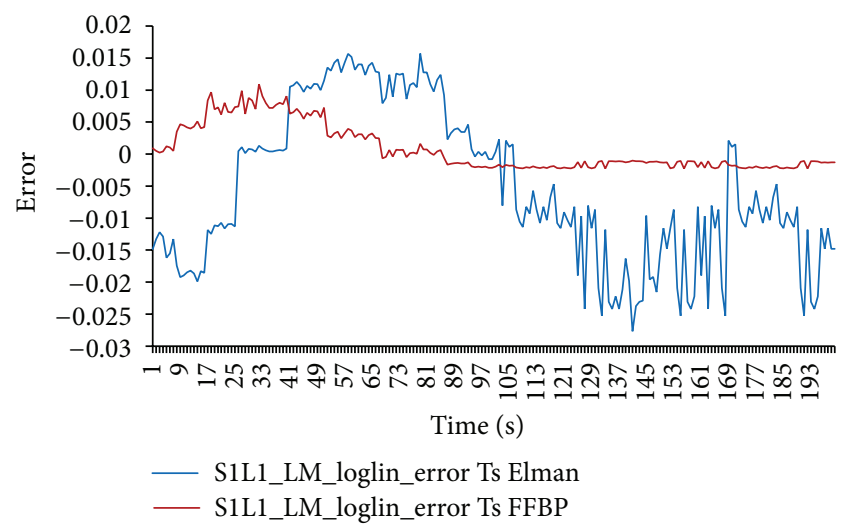

(a)

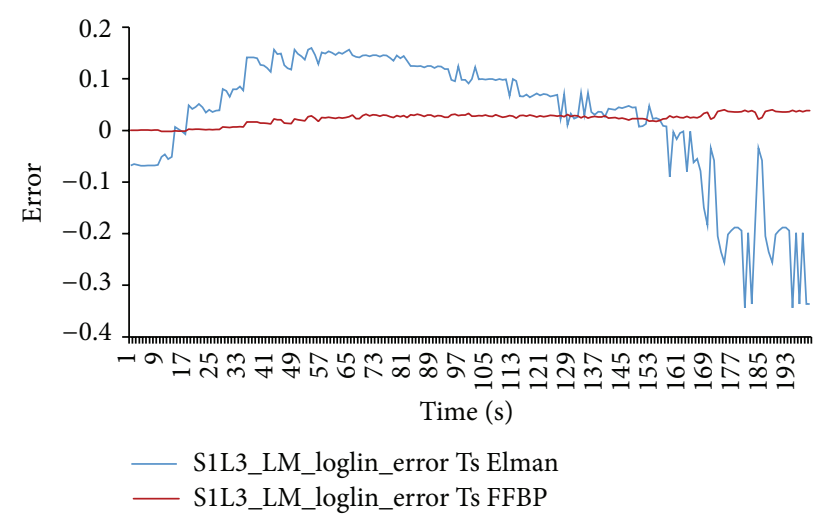

(c)

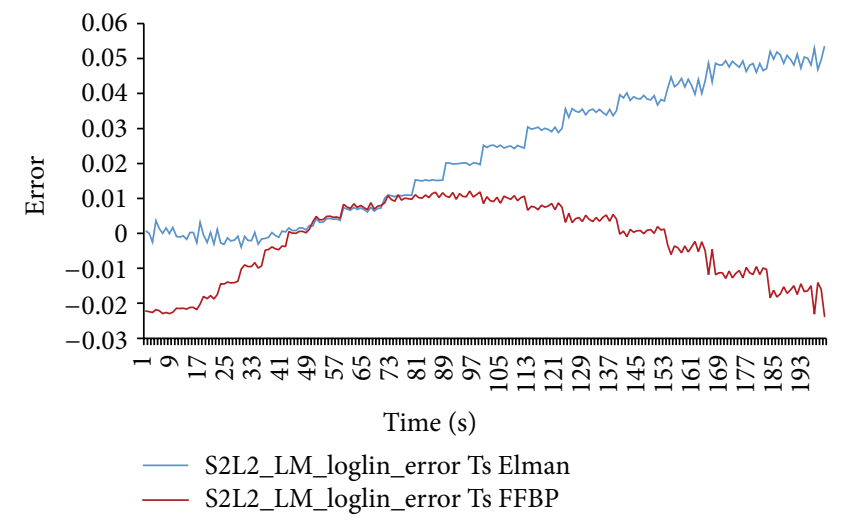

(e)

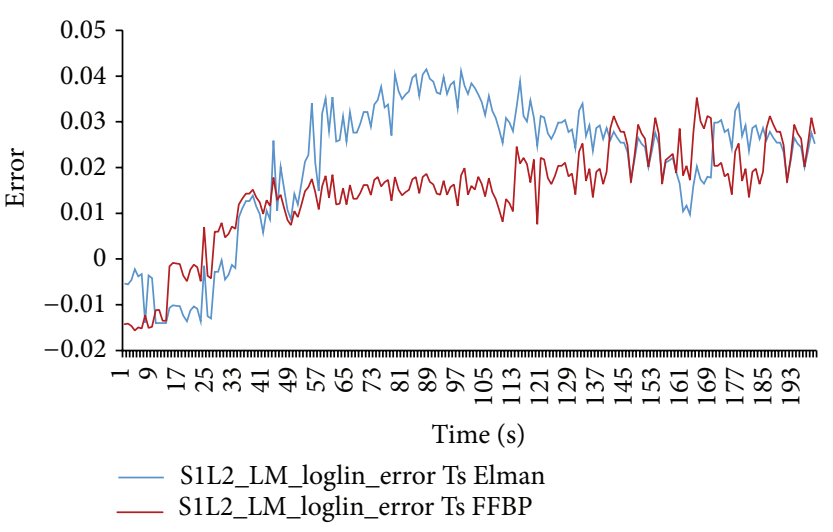

(b)

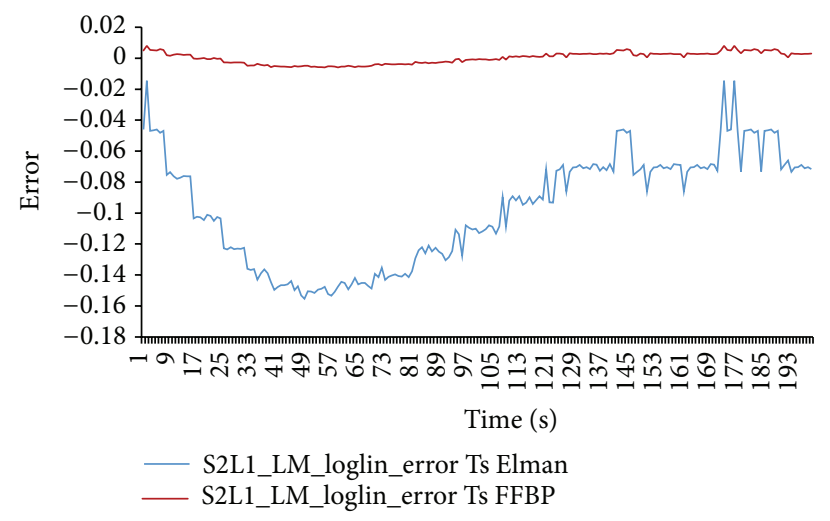

(d)

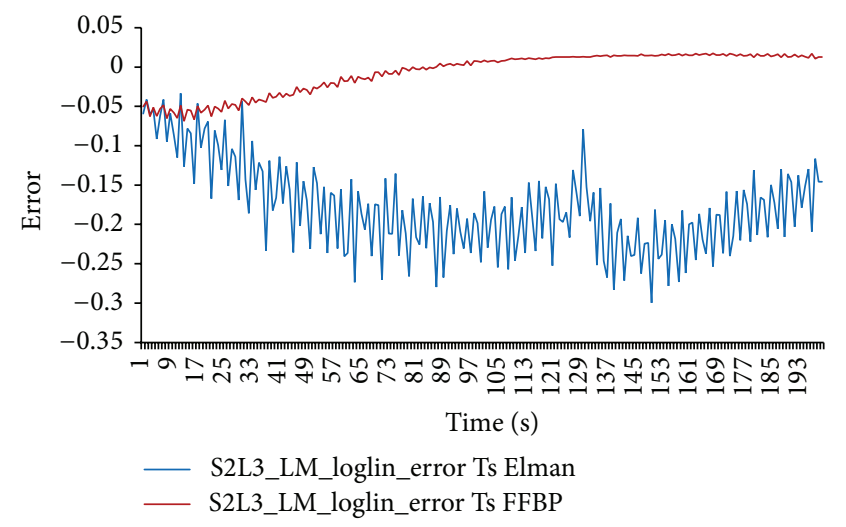

(f)

Figure 14: Compression between Elman and FFBP network testing error. (a) S1L1, (b) S1L2, (c) S1L3, (d) S2L1, (e) S2L2, and (f) S2L3. 
TABLE 7: Networks classification success results.

\begin{tabular}{lcccc}
\hline \multirow{2}{*}{ Load and speed condition } & \multicolumn{2}{c}{ FFBP network } & \multicolumn{2}{c}{ Elman network } \\
& Training classification & Testing classification & Training classification & Testing classification \\
\hline S1L1 & $100 \%$ & $100 \%$ & $100 \%$ & $100 \%$ \\
S1L2 & $100 \%$ & $100 \%$ & $100 \%$ & $100 \%$ \\
S1L3 & $100 \%$ & $100 \%$ & $100 \%$ & $99.5 \%$ \\
S2L1 & $100 \%$ & $100 \%$ & $100 \%$ & $99.2 \%$ \\
S2L2 & $100 \%$ & $99.7 \%$ & $100 \%$ & $99.5 \%$ \\
S2L3 & $100 \%$ & $99.7 \%$ & $100 \%$ & $99.6 \%$ \\
\hline
\end{tabular}

Figure 14 represents the output error for the Elman and FFBP network during testing. The testing output error represents the differences between the testing target and the testing prediction output

Testing output error (Tse)

$$
=\text { testing target }- \text { testing prediction output Ts. }
$$

From this figure it can be seen that the FFBP network testing error was smaller than the Elman testing error. This means that the predicted output from the FFBP network is more accurate than Elman and is almost the same as the target.

Classification program is designed and used to classify the oil film regime in gear, the program used with estimated data. When the two networks were tested with input data sets and targeted outputs, the networks yielded a predicted output. This output was used in the program. In this way, the result, as shown in Table 7, was obtained. The result of this comparison demonstrates that EN and FFBP have the ability to give superior performances of classification accuracy.

At the end, the two networks can be utilized in industry fields for condition monitoring of oil regime in gear, since the oil film thickness problems could be identified and alarmed through a comparison between actual and estimated thickness. The appropriate messages are generated if the estimated levels of any input variables differ significantly from the nominal level over a period of time.

The use of ANN in rotating machine condition monitoring based on acoustic emission signal is very rare. Therefore we cannot do any comparison between this work and other researchers' works, because most of researchers used vibration data as input and output of ANN. Sreepradha et al. [1] only used vibration data from two sensors, torque of the motor, and the temperature as inputs of ANN, while the output was oil film thickness. The approach of this work is by using FFBB and Elman networks for condition monitoring of lubricating oil in spur gears. Based on acoustic emission signal and oil temperature, ANN algorithm predicts film thickness in order to classify oil conditions as hydrodynamic lubrication, elastohydrodynamic lubrication, and boundary lubrication that help in finding faults during operation of gears.

\section{Conclusion}

An ANN techniques approach was proposed to improve the accuracy of oil film thickness prediction for spur gear.
The results showed that FFBP and Elman models were effective and this suggested technique attained $100 \%$ success in prediction and classification at high speed during training. The FFBP is better than Elman during testing and gives very good result in prediction and classification. The present study concludes that FFBP is better than EN, with better performance, prediction, classification, and less error. The architecture and topology of the network through specific systems can be used for online monitoring of oil film thickness and to predict any causes of failure of spur gear operation.

\section{Conflict of Interests}

The authors declare that there is no conflict of interests regarding the publication of this paper.

\section{References}

[1] C. Sreepradha, A. K. Kumari, A. E. Perumal, R. C. Panda, K. Harshabardhan, and M. Aribalagan, "Neural network model for condition monitoring of wear and film thickness in a gearbox," Neural Computing and Applications, vol. 24, no. 7-8, pp. 19431952, 2014

[2] B. Samanta, K. R. Al-Balushi, and S. A. Al-Araimi, "Artificial neural networks and support vector machines with genetic algorithm for bearing fault detection," Engineering Applications of Artificial Intelligence, vol. 16, no. 7-8, pp. 657-665, 2003.

[3] Z. Peng and N. Kessissoglou, "An integrated approach to fault diagnosis of machinery using wear debris and vibration analysis," Wear, vol. 255, no. 7-12, pp. 1221-1232, 2003.

[4] A. K. Mahamad and T. Hiyama, "Fault classification based artificial intelligent methods of induction motor bearing," International Journal of Innovative Computing, Information and Control, vol. 7, no. 9, pp. 5477-5494, 2011.

[5] C. K. Sung, H. M. Tai, and C. W. Chen, "Locating defects of a gear system by the technique of wavelet transform," Mechanism and Machine Theory, vol. 35, no. 8, pp. 1169-1182, 2000.

[6] M. Amarnath, C. Sujatha, and S. Swarnamani, "Experimental studies on the effects of reduction in gear tooth stiffness and lubricant film thickness in a spur geared system," Tribology International, vol. 42, no. 2, pp. 340-352, 2009.

[7] R. I. Raja Hamzah and D. Mba, "Acoustic emission and specific film thickness for operating spur gears," Journal of Tribology, vol. 129, no. 4, pp. 860-867, 2007.

[8] B.-R. Höhn and K. Michaelis, "Influence of oil temperature on gear failures," Tribology International, vol. 37, no. 2, pp. 103-109, 2004. 
[9] R. I. R. Hamzah and D. Mba, "The influence of operating condition on acoustic emission (AE) generation during meshing of helical and spur gear," Tribology International, vol. 42, no. 1, pp. 3-14, 2009.

[10] R. R. Hamzah, K. R. Al-Balushi, and D. Mba, "Observations of acoustic emission under conditions of varying specific film thickness for meshing spur and helical gears," Journal of Tribology, vol. 130, no. 2, pp. 1-12, 2008.

[11] M. Hamel, A. Addali, and D. Mba, "Monitoring oil film regimes with acoustic emission," Proceedings of the Institution of Mechanical Engineers, Part J: Journal of Engineering Tribology, vol. 228, no. 2, pp. 223-231, 2014.

[12] B. Samanta and K. R. Al-Balushi, "Artificial neural network based fault diagnostics of rolling element bearings using timedomain features," Mechanical Systems and Signal Processing, vol. 17, no. 2, pp. 317-328, 2003.

[13] B. Samanta, "Gear fault detection using artificial neural networks and support vector machines with genetic algorithms," Mechanical Systems and Signal Processing, vol. 18, no. 3, pp. 625644, 2004.

[14] S. Rajakarunakaran, P. Venkumar, D. Devaraj, and K. S. P. Rao, "Artificial neural network approach for fault detection in rotary system," Applied Soft Computing Journal, vol. 8, no. 1, pp. 740$748,2008$.

[15] Y. Lei, Z. He, Y. Zi, and Q. Hu, "Fault diagnosis of rotating machinery based on multiple ANFIS combination with GAs," Mechanical Systems and Signal Processing, vol. 21, no. 5, pp. 2280-2294, 2007.

[16] J. M. F. Salido and S. Murakami, "A comparison of two learning mechanisms for the automatic design of fuzzy diagnosis systems for rotating machinery," Applied Soft Computing Journal, vol. 4, no. 4, pp. 413-422, 2004.

[17] Q. Hu, Z. He, Z. Zhang, and Y. Zi, "Fault diagnosis of rotating machinery based on improved wavelet package transform and SVMs ensemble," Mechanical Systems and Signal Processing, vol. 21, no. 2, pp. 688-705, 2007.

[18] Y. Yang, D. Yu, and J. Cheng, "A fault diagnosis approach for roller bearing based on IMF envelope spectrum and SVM," Measurement, vol. 40, no. 9-10, pp. 943-950, 2007.

[19] Y. Lei, Z. He, Y. Zi, and X. Chen, "New clustering algorithmbased fault diagnosis using compensation distance evaluation technique," Mechanical Systems and Signal Processing, vol. 22, no. 2, pp. 419-435, 2008.

[20] M. Hamel, A. Addali, and D. Mba, "Investigation of the influence of oil film thickness on helical gear defect detection using Acoustic Emission," Applied Acoustics, vol. 79, pp. 42-46, 2014.

[21] Y. H. Ali, R. Abd Rahman, and R. I. R. Hamzah, "Acoustic emission signal analysis and artificial intelligence techniques in machine condition monitoring and fault diagnosis: a review," Jurnal Teknologi, vol. 69, no. 2, 2014.

[22] Y. H. Ali, M. R. Omar, R. A. Abd Rahman, and R. I. R. Hamzah, "Acoustic emission technique in condition monitoring and fault diagnosis of gears and bearings," International Journal of Academic Research Part A, vol. 6, no. 5, article 6, 2014.

[23] C. K. Tan and D. Mba, "Identification of the acoustic emission source during a comparative study on diagnosis of a spur gearbox," Tribology International, vol. 38, no. 5, pp. 469-480, 2005.

[24] K. P. Ferentinos, "Biological engineering applications of feedforward neural networks designed and parameterized by genetic algorithms," Neural Networks, vol. 18, no. 7, pp. 934-950, 2005.
[25] J. Rafiee, F. Arvani, A. Harifi, and M. H. Sadeghi, "Intelligent condition monitoring of a gearbox using artificial neural network," Mechanical Systems and Signal Processing, vol. 21, no. 4, pp. 1746-1754, 2007.

[26] A. K. Mahamad, S. Saon, and T. Hiyama, "Predicting remaining useful life of rotating machinery based artificial neural network," Computers and Mathematics with Applications, vol. 60, no. 4, pp. 1078-1087, 2010.

[27] K. G. Sheela and S. N. Deepa, "Review on methods to fix number of hidden neurons in neural networks," Mathematical Problems in Engineering, vol. 2013, Article ID 425740, 11 pages, 2013. 

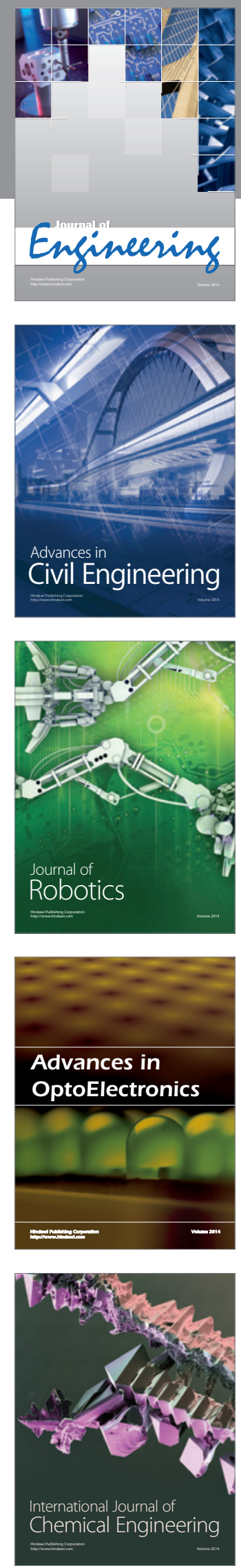

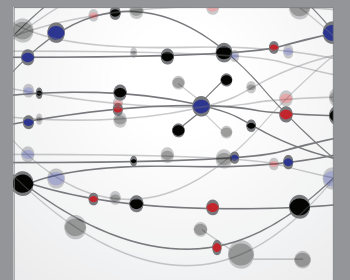

The Scientific World Journal
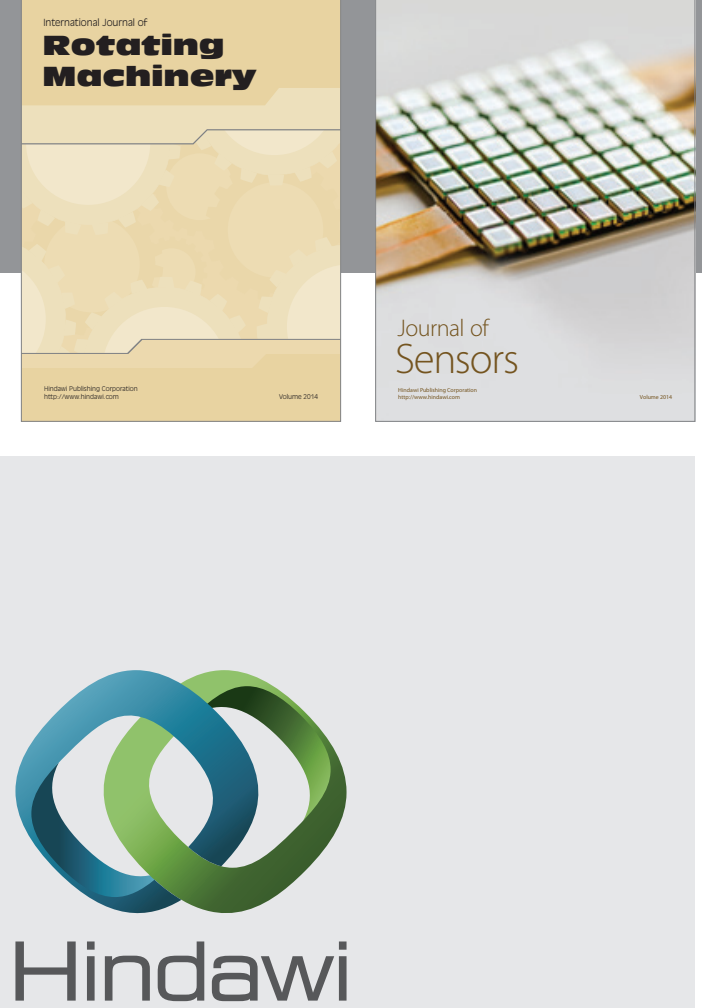

Submit your manuscripts at http://www.hindawi.com
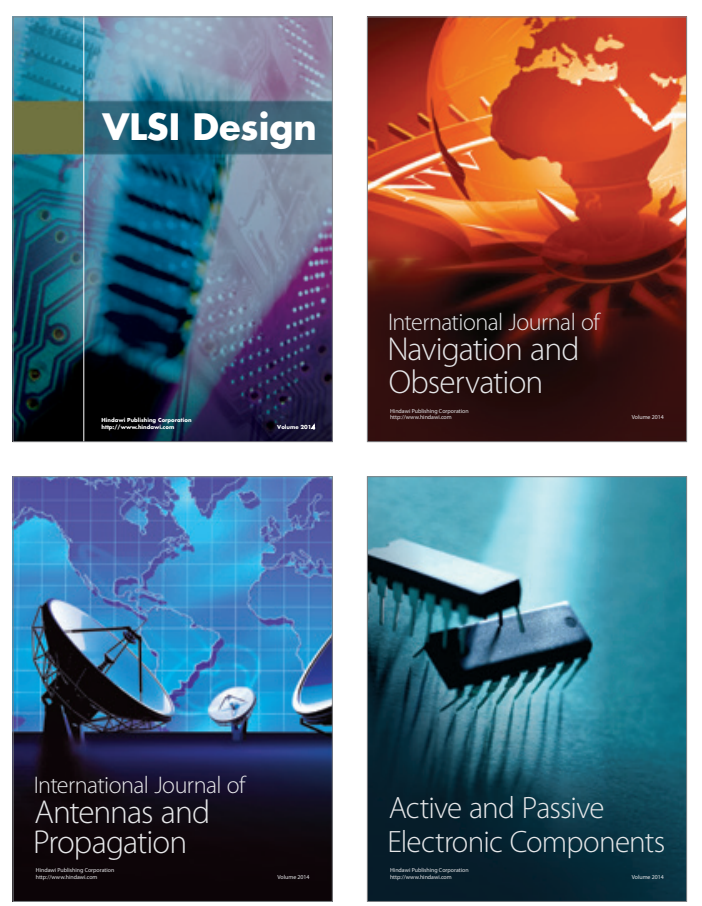
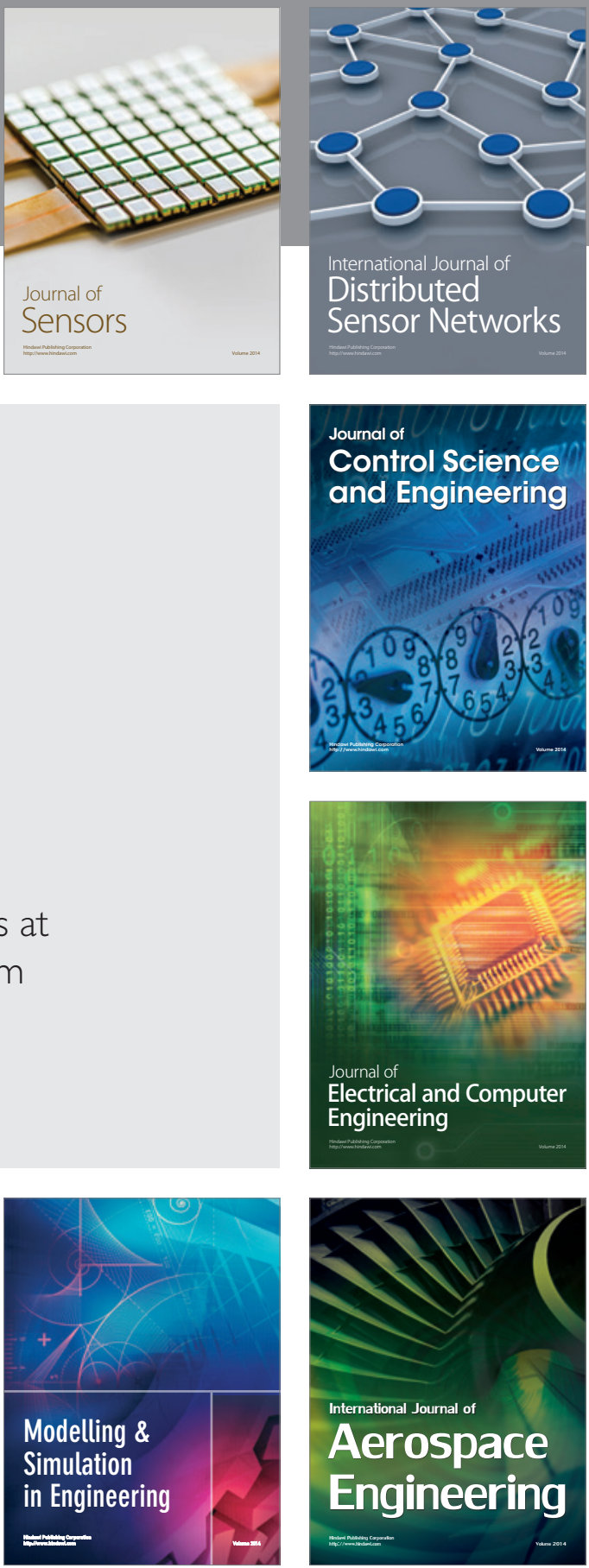

Journal of

Control Science

and Engineering
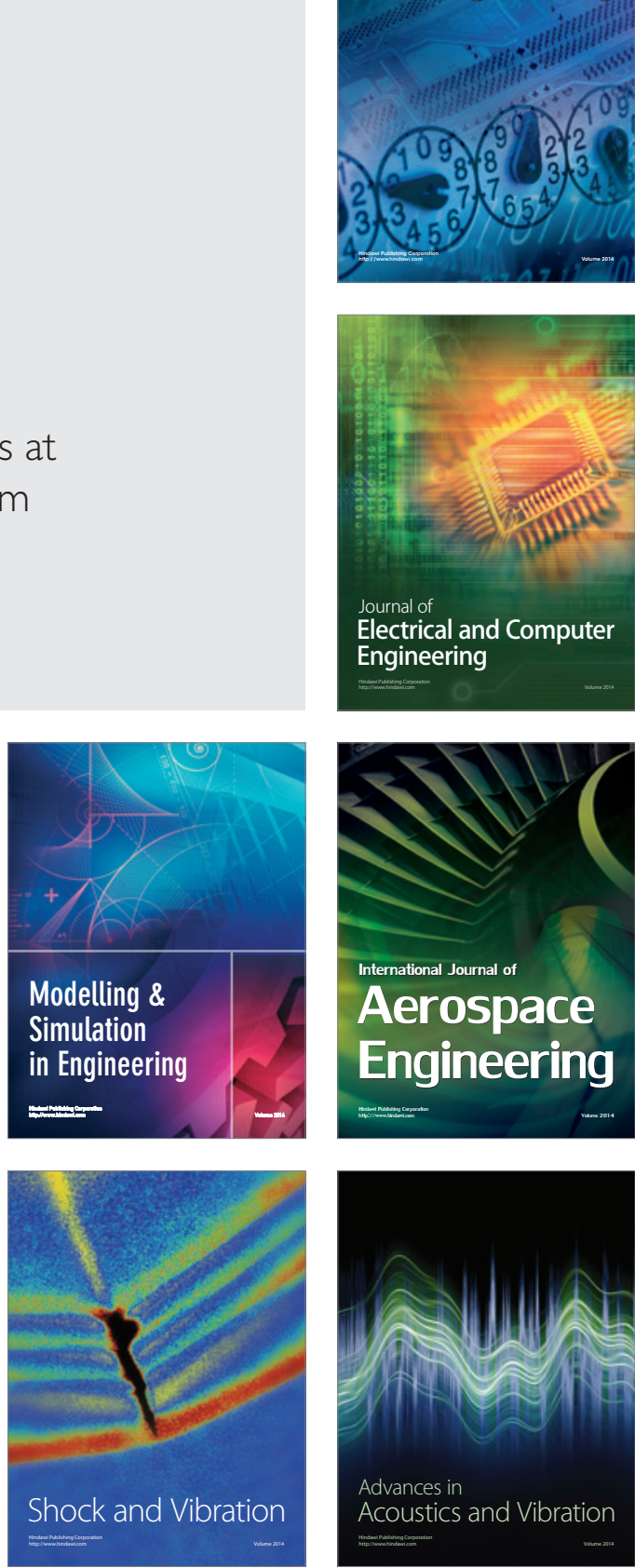